\title{
MOMENTUM EFFECTS IN COUNTRY EQUITY INDICES
}

\author{
C Muller and M Ward*
}

Abstract
This paper examines the 70 country indices which comprise the
MSCl world index as a representative set of global equity
investment opportunities, and examines momentum and mean-
reversion effects in these. We show that persistent and significant
effects do exist, particularly with regard to short-term momentum. A
strategy of holding for one month, a portfolio of the four best
performing MSCl country indices over the previous 11 months, was
found to persistently out-perform an equal weighted benchmark by
around $10 \%$ per annum over the 39 year period from 1970 to 2009 .

\section{Introduction}

The simplicity and theoretical elegance of the Capital Asset Pricing Model (CAPM) have resulted in this single factor asset-pricing model constituting the mainstay of many investment models. Although alternative models, such as Arbitrage Pricing Theory (Ross, 1976) and the Fama-French Three-Factor Model (Fama and French, 1992) have sought to overcome several empirical shortcomings of the CAPM, researchers have found that investors do not act in accordance with these theories, and have blended psychology with finance to form the field of behavioural finance. In particular, evidence has been reported of short term momentum effects, in that shares which out-perform continue to out-perform. Similarly, a long term meanreversion or over-reaction effect has shown that shares which have underperformed for around five years tend to out-perform thereafter (Jegadeesh and Titman, 1993; De Bondt and Thaler, 1985).

The relatively recent innovation of exchange traded funds (ETFs) on stock market indices provides an attractive vehicle for investors seeking low-cost, geographically diversified assets. The MSCI World Index comprises 70 country indices, on a market capitalisation weighted basis, with no over-lapping ${ }^{1}$ shares. Historical total return data for the individual underlying country indices is available from their

\footnotetext{
* Absa Chair Finance and Gordon Institute of Business Science, University of Pretoria 0001, Republic of South Africa.

Email: mchlwrd@gmail.com

${ }^{1}$ i.e. All the assets of dual and multi-listed shares are ascribed to their major country index to avoid double-counting.
} 
database in both local currencies and US dollars. This makes it possible to examine the returns that would have been achieved by purchasing a well diversified, equal weighted portfolio of country indices as a benchmark to investigate momentum effects on portfolios of country indices. Such a strategy is attractive because trading strategies on single shares have been shown to be 'traded-out' as increasing numbers of fund managers mimic the strategy. Country indices, on account of their significantly larger underlying market capitalisations, are likely to show more persistent momentum.

\section{Literature review}

Eugene Fama's Efficient Market Hypothesis (Fama, 1970) initially attracted considerable support amongst academics. In an efficient market, momentum effects and price reversals would not be evident. Indeed, Fama and French (1996) suggest that once other known market effects such as the size effect and the value/growth effect are removed from the data, there is little evidence of share price overreaction or reversal, particularly if transaction costs are included (see also Fama, 1998; Cochrane, 2001). However, many other researchers have found, and continue to find, evidence of these effects.

De Bondt and Thaler (1985) report two observable patterns in share returns which they ascribe to the behaviour of market participants. They note a short-term positive momentum effect in share returns as well as a long-term reversal. Shares which had performed particularly well over the recent past were found to retain their momentum for a short period. Similarly, shares which had performed badly over a considerably longer period were likely to reverse their poor performance, and outperform over a long period.

A significant amount of research followed De Bondt and Thaler's seminal paper (see for example Jegadeesh and Titman, 1993 and 2001). The literature which followed offered several behavioural finance theories to explain these results. Some researchers ascribed share reversals to investor over-reaction. They suggested that a share might gain positive momentum as investors, noting positive short-term performance, 'piled in', creating a short-term bubble. Alternatively, a stock which exhibited poor returns would continue to do so as investors shunned the share, until it reached a point well below its fair value. Ultimately investors would realise this, and a consequent reversal ensured a period of out-performance.

Other behaviourists (see for example Bernard and Thomas, 1990 and Lakonishok and Vermaelen, 1990) ascribed the same empirical findings to investor underreaction, arguing that investors are too slow in incorporating news into share prices. In an efficient market, a 'good news' announcement ought to instantaneously reprice the share. If the market is inefficient and investors react slowly, the share price will gradually increase until the price reflects a consensus view of the revised 'fair' value.

Carhart (1997) documents the findings of several related studies regarding the performance of portfolio managers and notes that many researchers find evidence 
of short term (one to three year) persistent performance which they attribute to "hot hands" or common strategies (p 57). He notes that some evidence also exists for longer term persistence, which is ascribed to differential information or stock picking talent. Some of this performance, he asserts, relates to momentum effects. His own research however, shows that once the results are controlled for survivor bias, short term momentum and expense differentials, there is no evidence of "hothands'; the only exception being that poor performance persists.

Droms and Walker (2001) find evidence of persistent performance over one year (only) in their study of all international equity funds over the 20 year period 19771996. They conclude by stating that "international equity mutual funds exhibit strong persistent performance over one year", which generally fades thereafter ( $\mathrm{p}$ 237).

Moskowitz and Grinblatt (1999) find that industry effects produce stronger momentum effects than single stocks, and that a highly profitable trading strategy is possible. These findings are confirmed in a repeat study using large-cap US data from 1998-2007 by Fraulo and Nguyen (2009). In their follow-up study, Grinblatt and Moskowitz (2004) report evidence of momentum and tax-loss selling that they claim significantly affects returns. They show that a trading rule strategy based on their findings generates surprisingly large economic returns, even after controlling for bias.

George and Hwang (2004) investigate a momentum strategy in which the ratio of the current share price and the past 52 week high price is used as a momentum indicator. They find that such a strategy identifies the market peak and captures most of the momentum effect. They argue that the price level itself is a more important indicator of momentum effects than past price changes, and suggest that traders may use the 52 week high as an 'anchor' against which they reference the impact of further news.

These findings support evidence of short term momentum effects in single stocks. Furthermore, Moskowitz and Grinblatt (1999) suggest that these effects are even stronger in industries. Droms and Walker (2001) find momentum across international equity funds, and Grinblatt and Moskowitz (2004) show that a parsimonious trading rule can produce large economic returns. Following on the supporting evidence, this research examines momentum effects in country stock market indices, on the grounds that these are more likely to persist given their significantly greater underlying value, and may provide the basis of a profitable trading strategy.

\section{Methodology}

The MSCI database contains country stock market index data, commencing 1969, for 18 major markets. From 1987 MSCI include 18 more country indices to their data set, and periodically thereafter more countries are added, such that there are currently more than 70 time-series of different country indices in the data base, with historical data over varying periods. The indices reflect total returns to 
shareholders and are market capitalisation weighted. Since care has been exercised to ensure that the constituent companies in any country index represent only those with their primary listing in that country MSCI indices differ somewhat from those reported by the various stock exchanges. All the analysis in this paper is based on the US dollar denominated time series data provided by MSCI.

Two investment strategies are investigated in this study: upward momentum and mean reversion.

The upward momentum strategy is premised on prior research which has found short-term positive momentum in 'winning' shares. The underlying methodology for this strategy was to:

- $\quad$ rank country index performance over the past 'F' (formation) months

- $\quad$ invest in the top ' $\mathrm{N}$ ' performing countries

- $\quad$ construct an equal weighted portfolio of these $\mathrm{N}$ 'winner' countries

- $\quad$ sell after ' $\mathrm{H}$ ' (holding) months.

Similarly, the mean reversion strategy followed prior research which has found evidence of long-term mean reversion of 'losing' shares. The underlying methodology was to:

- $\quad$ rank country index performance over the past ' $F$ ' (formation) months

- $\quad$ invest in the worst ' $\mathrm{N}$ ' performing countries

- $\quad$ construct an equal weighted portfolio of these $\mathrm{N}$ 'loser' countries

- $\quad$ sell after 'H' (holding) months.

To minimise start-up date and timing effects, which have been found to exist in time-series data, a seeding process for the portfolio construction was devised. Initially all funds were assumed to be cash. If for example the holding period $(\mathrm{H})$ for the analysis was 25 months, then in the first month $1 / \mathrm{H}(4 \%)$ of the cash position was invested equally in the $\mathrm{N}$ country indices. At the next review period, one month later, an additional $1 / \mathrm{H}(4 \%)$ was taken from the cash position and invested in the (newly ranked) $\mathrm{N}$ countries. After $\mathrm{H}$ (25) months the cash would be fully invested, and the cash from the sale of the initial portfolio (now liquidated at market prices) would be re-invested into the newly ranked $\mathrm{N}$ countries. Consequently, a start-up period in which the fund was not fully invested would occur, but thereafter the trading strategy would determine performance as funds rolled from expired portfolios into new ones. To ensure comparability, the initial seeding period was ignored in the analysis.

This process is repeated for all combinations of $\mathrm{H}, \mathrm{F}$ and $\mathrm{N}$ and in each case the resulting portfolio's value noted and represented graphically. The outcome of each analysis is benchmarked against an equal weighted portfolio of all the countries used in the sample, to determine the extent of over/under performance during the period. The benchmark index was constructed exactly as described above, the only difference being that all the countries in the sample were included (i.e. F=9999). This ensured that the benchmark was re-weighted (equally) at the end of the 
holding period $\mathrm{H}$, coinciding with the trading portfolio. Based on prior research we expect 'winning' shares to (briefly) continue with upward momentum before being over-bought whereas 'losers' would be expected to revert to levels above their intrinsic value over a much longer recovery period.

Since the methodology effectively 'data mines' the time series using in-sample data, one cannot be certain that the results hold in a general sense. To overcome this concern, two approaches were followed:

Firstly, in the initial sample, the first tier of 18 countries was analysed over their full history (31 December 1969 - 31 December 2008). As can be seen in Figure 2, this sample represented large developed countries, and is referred to as "Top 18" hereafter. The second sample used a new data set (the second tier of 18 countries, "Next 18") for the period 31 December 1987 - 31 December 2008. These 18 countries were added to the MSCI database from 31 December 1987 and constitute smaller, developing countries (see Figure 8). Finally, a third sample, commencing on 31 December 1969, but which included any country into the analysis as the data became available, was analysed. From December 1969 to December 1987 the third sample only included Top 18 countries. From December 1987 to December 1992 it included Top 18 and Next 18 countries, and thereafter the size of the sample grew as shown in Figure 1, as data from emerging countries became available. By repeating the study using countries with different geographies and economies, as well as over different (although overlapping) time periods, it was hoped that concerns of data mining would be allayed, providing the results were consistent across the three samples.

Secondly, the results were plotted graphically, and a 'price-relative' indicator was calculated as the (value of the portfolio)/(value of the benchmark). The price/relative shows the periods in which the strategy out-performs the benchmark (the slope of the price-relative is upwards) and the periods in which the strategy under-performs (the slope is downwards). This is useful in that if the price relative is generally upward sloping, the strategy shows persistence. If this is not the case then it can be assumed that the market has traded-out any momentum effects over time, and although the strategy may have worked for a period of time, it lacks persistence. Classical data mining can result in concentrated effects in specific time periods being averaged across the study. This methodology permits a continuous assessment of whether or not an effect is working, and highlights periods when the effect is most prevalent.

\section{4. $\quad$ Results}

The results of the research are presented graphically. Figure 1 below shows the number of country indices available in the MSCI database over time:

As can be seen from Figure 1, from December $31^{\text {st }} 1969$ only 18 country indices are available in the dataset, and these are used as the first sample. At the end of 1987 a further 18 are added, and these are used as the second sample. Thereafter, country indices are periodically included and by 2009, 70 country indices are available. In 
the third and final sample we repeat the analysis using all the indices, including each one into the sample as they enter the dataset, commencing in 1969 and ending 31 December 2008.

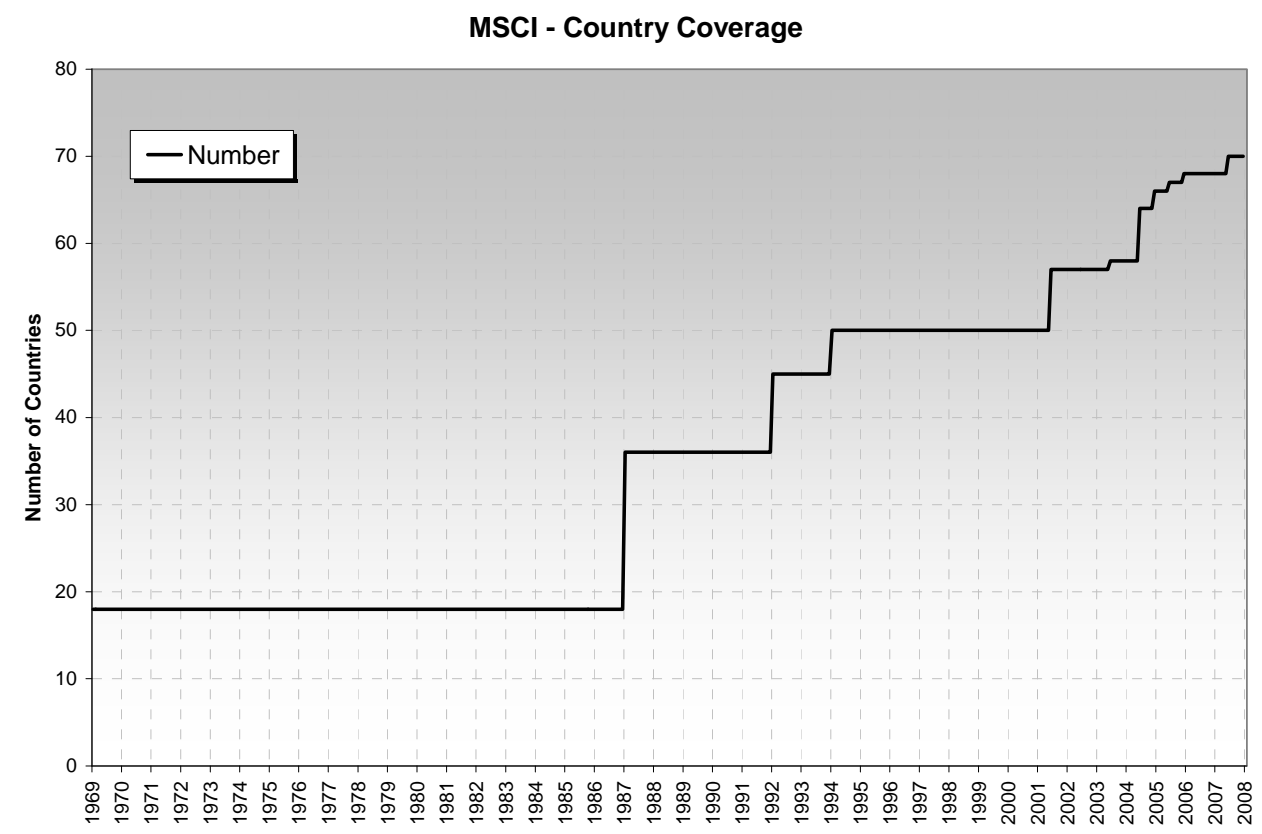

Figure 1: The number of country indices in the MSCI data base. These are all total shareholder return indices, and market capitalisation weighted.

Figure 2, by way of illustration, shows the annualised 40 year returns for tier 1 , the top 18 countries, expressed in US\$:

Figure 2 shows that over the period 31 December 1969 to 31 December 2008 the total return in USD to shareholders was highest in Hong Kong, with an annualised return of $14.7 \%$. Italy showed the worst performance at only $6 \%$, with the USA ranked $15^{\text {th }}$ at $9,1 \%$.

Figure 3 presents the results from the 'loser' analysis of the Top 18 countries. The method ranks country returns over a 'look-back' or formation period of F months using prior data, selects the worst $\mathrm{N}$ shares and invests in an equal-weighted portfolio of these shares for the following $\mathrm{H}$ months to see how they perform. The out-performance against the equal-weighted return of a portfolio comprising all Top 18 indices is calculated over the matching holding periods. 


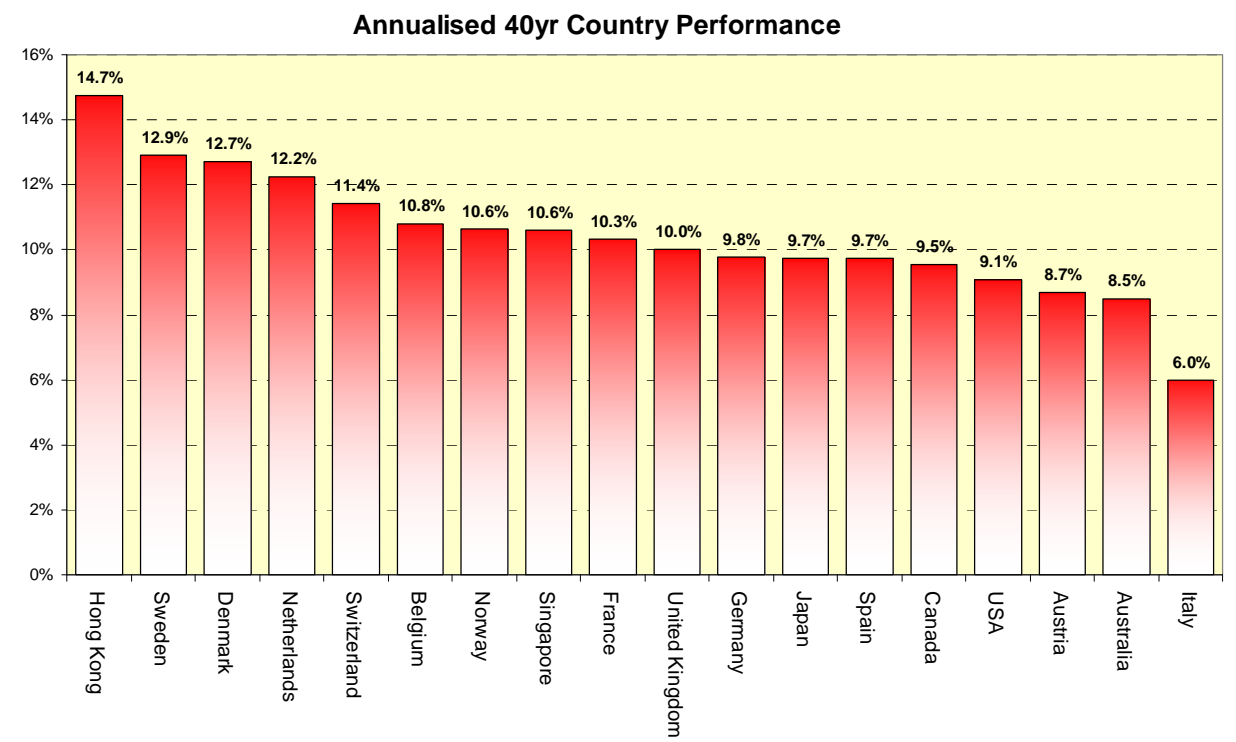

Figure 2: Annualised 40 year total returns for the top 18 country indices. This analysis assumes a single lump-sum investment on 31 December 1969 held until 31 Dec 2008

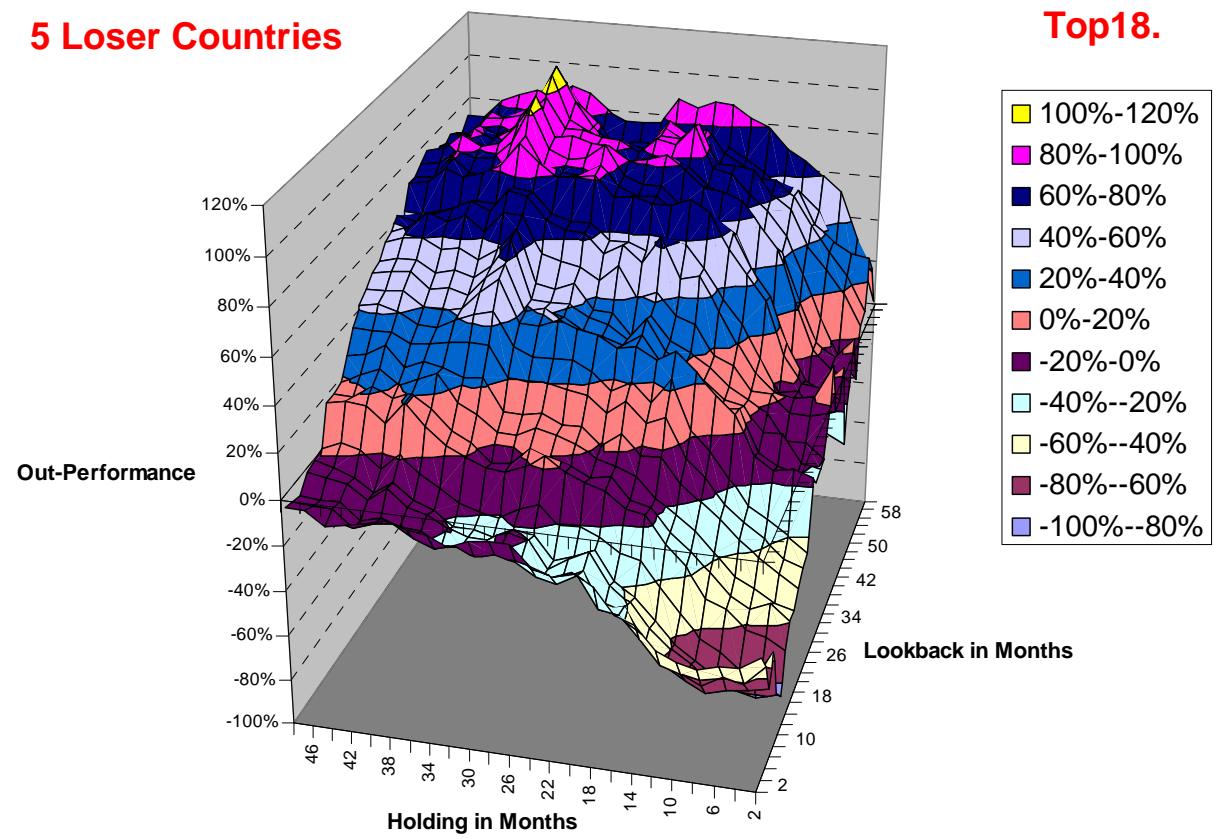

Figure 3: Surface plot of out-performance of 'loser' portfolios containing 5 shares for the Top 18 sample over the period 1969-2008. 
As can be seen from Figure 3, a reasonably smooth surface emerges from the analysis. For combinations of short formation (lookback period) and short holding periods the strategy underperforms the benchmark. However, as the formation period lengthens to around 40 months, and the holding period lengthens to around 30 months, a plateau forms, with very attractive out-performance levels of between $60 \%$ and $80 \%$ over the period. The best result (108\%) is achieved with a formation period of 54 months and a holding period of 36 months on a portfolio comprising the 5 worst 'Losers'.

Figure 4 shows a plot of the percentage contribution to the final portfolio return as the portfolio size $(\mathrm{N})$ is increased by additional countries from 1 country to 18 :

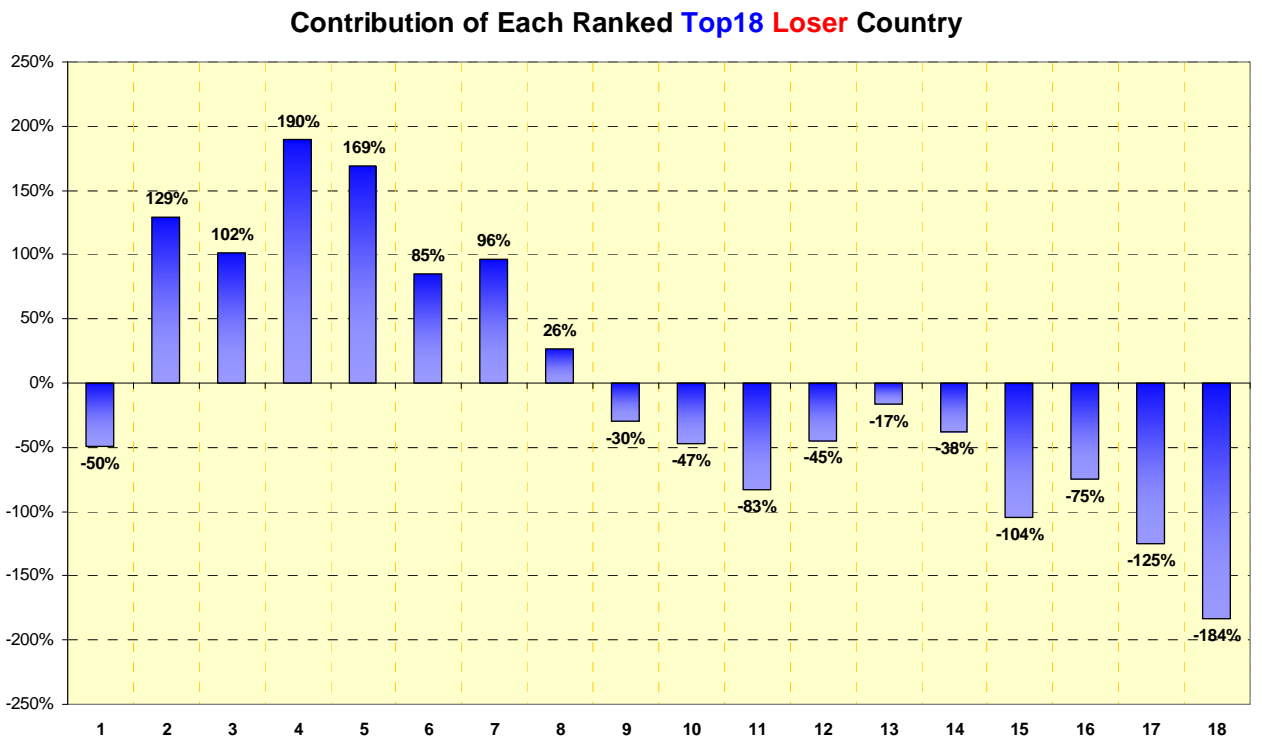

Figure 4: Contribution to out-performance as the portfolio size $\mathbf{N}$ is increased.

Figure 4 shows that the worst eight ranked (except the very worst) 'loser' countries contribute to the out-performance of the strategy. A portfolio consisting of the worst five 'loser' countries produced the highest average contribution (i.e. those ranked six, seven and eight reduce the average) and these are used in the analysis over the period as shown in Figure 5 below.

Figure 5 shows how the trading strategy outperforms the Top 18 equal weighted benchmark. A R1 investment in 1977 would have been worth R84 on 31 December 2008, versus R39 in the benchmark. The slope of the price relative (plotted against the right hand axis and amplified using a linear scale) shows that the strategy only works over the period 1977-1992. Thereafter the slope of the price-relative is stationary, indicating that momentum effects have been traded out, and the strategy has stoped working. 


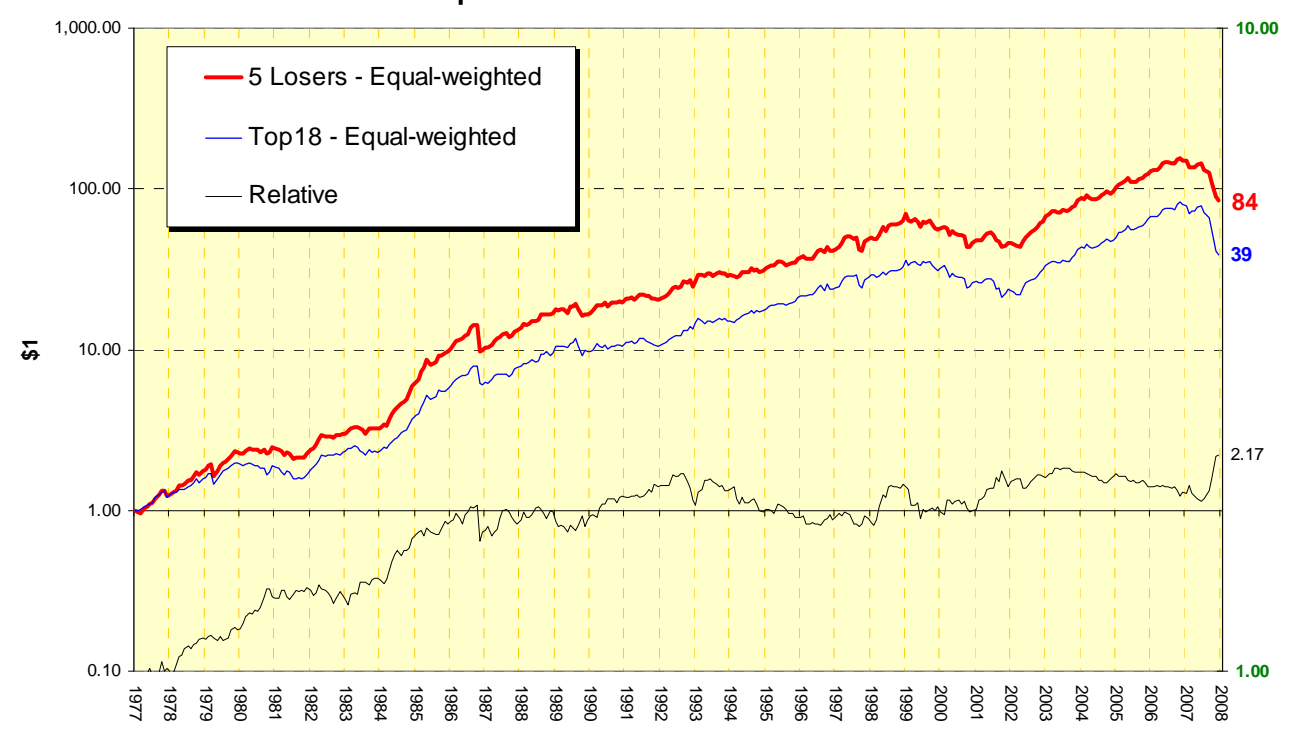

Figure 5: The performance of the portfolio of 5 'losers' in the Top 18 sample.

An analysis of the 'winners' strategy for differing combinations of formation and holding periods produced the surface shown in Figure 6:

Figure 6 shows a significantly more 'peaked' surface plot of the results. From the shape of the surface plot it can be seen that any strategy using a short formation (lookback) period of between 5 and 15 months, in combination with a holding period of up to 6 months, would have shown out-performance of $200 \%$ or more over the period. The combination of a 10 month formation period and a two month holding period achieved an incredible 432\% out-performance over the period against the benchmark with a portfolio of the five (highest ranked) shares.

Figure 7 shows the time series performance of the winner strategy against the benchmark over the period 31 December 1969 - 31 December 2008:

Figure 7 shows that a trading strategy of forming portfolios by equally weighting the highest ranked 5 countries over the preceding 10 months and holding these for the next 2 months significantly out-performs the equal weighted index of the Top 18 countries. Over the 40 year period the strategy generates a $17.7 \%$ annualised return, significantly in excess of the equal weighted index (12.4\%). Furthermore, the slope of the price-relative (plotted on the right-hand axis) is consistently upward, showing that the winner strategy persistently out-performs the benchmark, and is not period specific. 


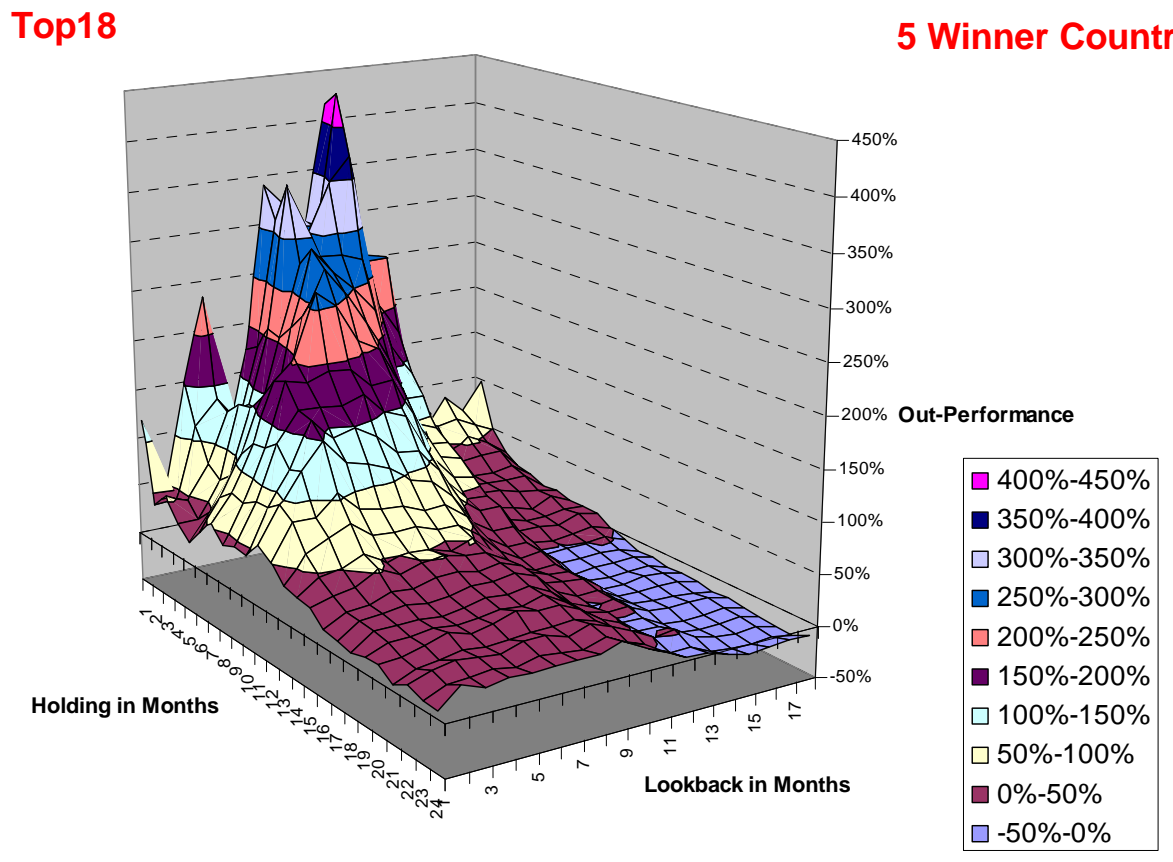

Figure 6: Surface plot of out-performance of 'winner' portfolios containing 5 shares for the Top 18 sample over the 39 year period 1969-2008.

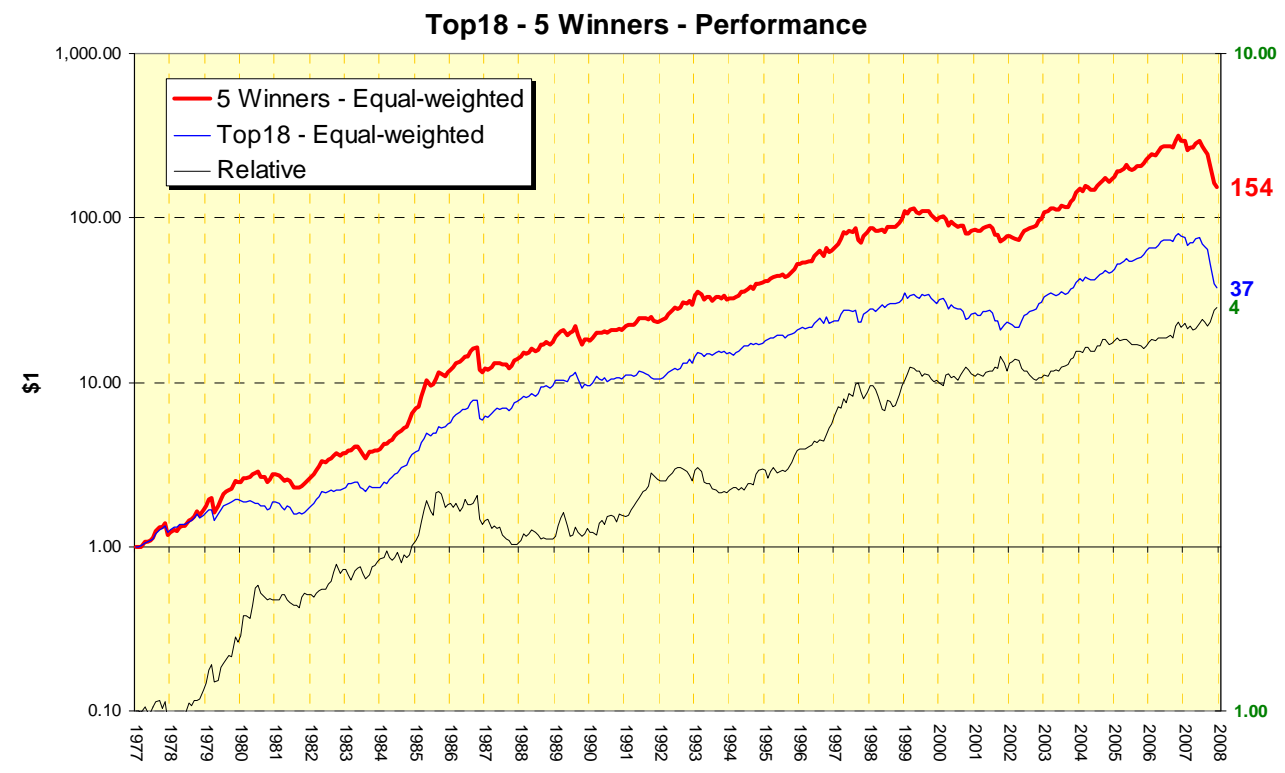

Figure 7: The performance of the portfolio of 5 winners in the 18 countries comprising the Top 18. 
Following the same methodology, the analysis was repeated for both the 'loser' and 'winner' strategies, but using the Next 18 countries over the period 1987 to 2008. Figure 8 shows the constituent countries of the Next 18 sample and their annualised performance over the 21 year period:

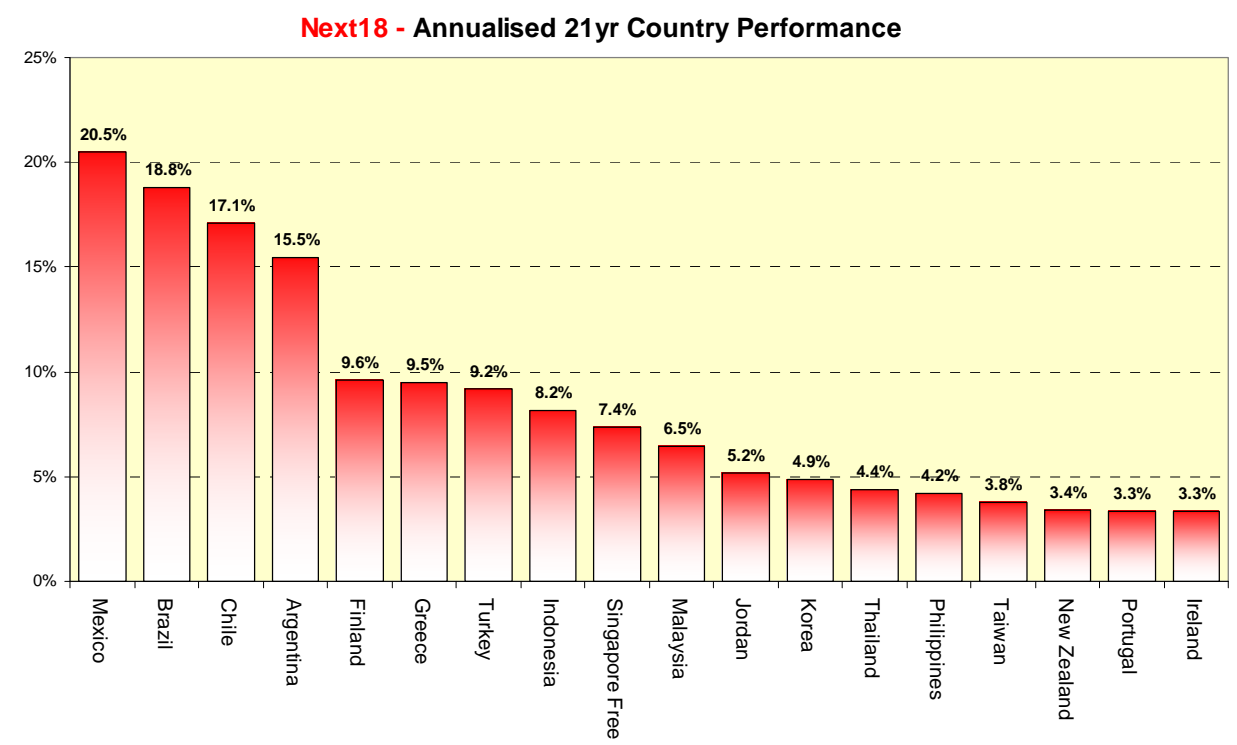

Figure 8: Annualised returns for next 18 country indices. This analysis assumes a single lump-sum USD investment on 31 December 1986 held until 31 December 2008.

Figure 8 shows that the best performing countries were in Latin America, with Mexico and Brazil reflecting significantly higher annualised returns in USD terms than the Top 18 countries, at 20,5\% and 18,8\% respectively. Ireland and Portugal were the worst performers with annualised returns of only 3,3\% each.

The 'loser' strategy produced a surface plot similar to Figure 4, and the best result was achieved for a portfolio of four equal weighted country indices, using a formation period of 56 months and holding for the following 22 months. Figure 9 shows the performance time-series over the 21 years:

From Figure 9 it can be seen that the 'loser' strategy using the Next 18 sample outperforms the equal weighted benchmark of these 18 countries. This meanreversion trading strategy showed an annualised return of $20.7 \%$, double that of the benchmark at $10.3 \%$. As with the 'loser' strategy in the Top 18 sample, the slope of the price-relative appears to decline after the peak in 1988, indicating that the strategy's effectiveness waned in the second half of the analysis period. 


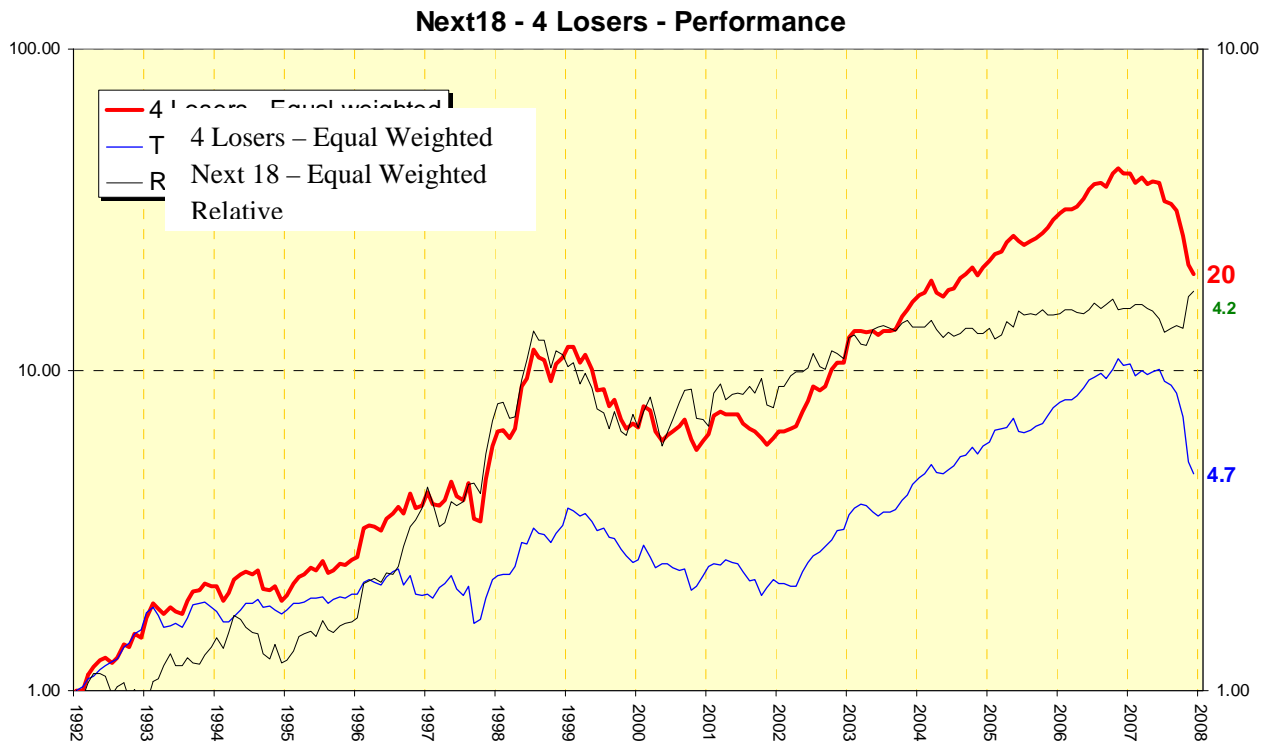

Figure 9: The performance of the portfolio of 4 losers in the Next 18 sample.

For the 'winner' strategy, the best result was achieved for a portfolio of six equal weighted country indices using a formation period of 10 months and holding for the following one month. Figure 10 shows the performance chart over the 21 years:

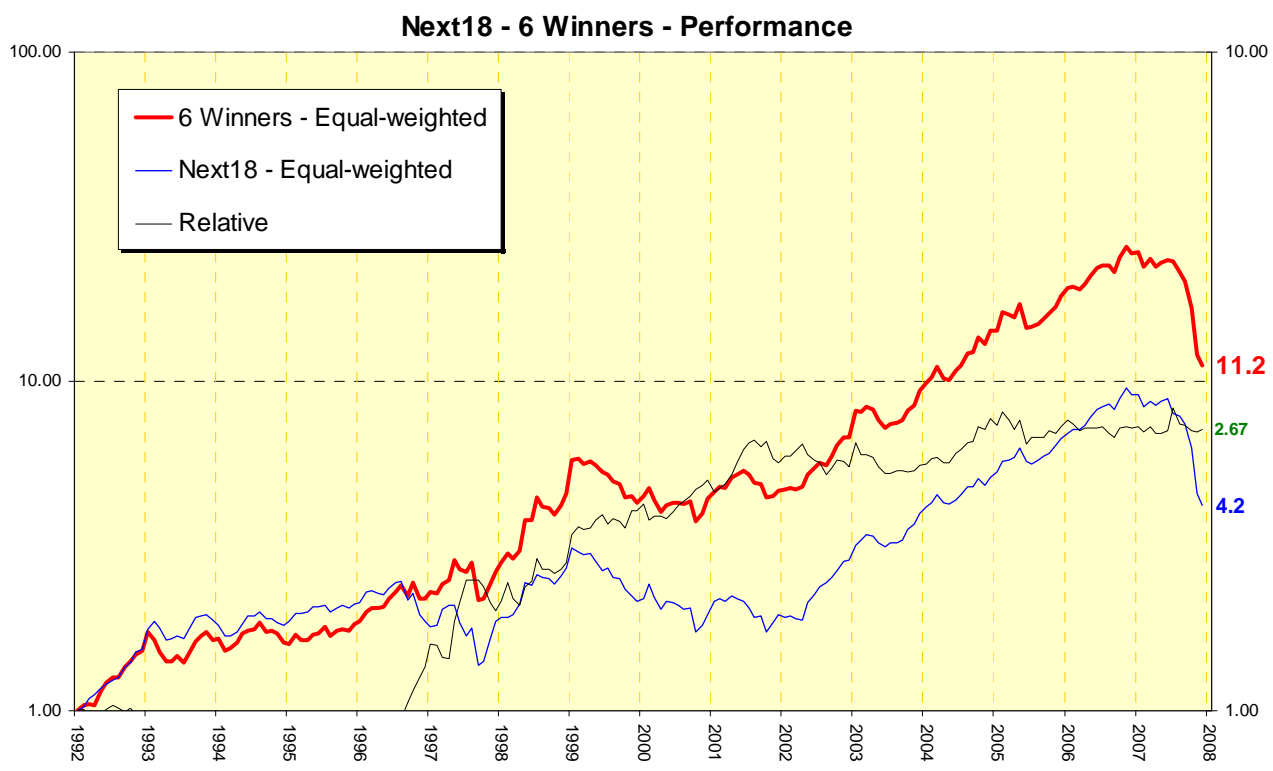

Figure 10: The performance of the portfolio of 6 'winners' in the Next 18 sample. 
From Figure 10 it can be seen that the 'winner' strategy using the Next 18 country indices outperforms the equal weighted index. This momentum based trading strategy achieved an annualised return of $16.4 \%$ over the period, significantly better than the benchmark at $9.4 \%$. For the initial 5 years however, the slope of the price relative was below 1 indicating some under-performance, thereafter the strategy appears to work well, albeit with declining influence over the last three years.

As a final test of these strategies, the analysis was re-run using the entire data-set from December 1969, and including new countries as their data became available. As before, all the combinations of look-back $(\mathrm{L})$ and holding $(\mathrm{H})$ periods, for different numbers of countries $(\mathrm{N})$ in the sample, were analysed on an ex-post. Figures 11 and 12 present the results.

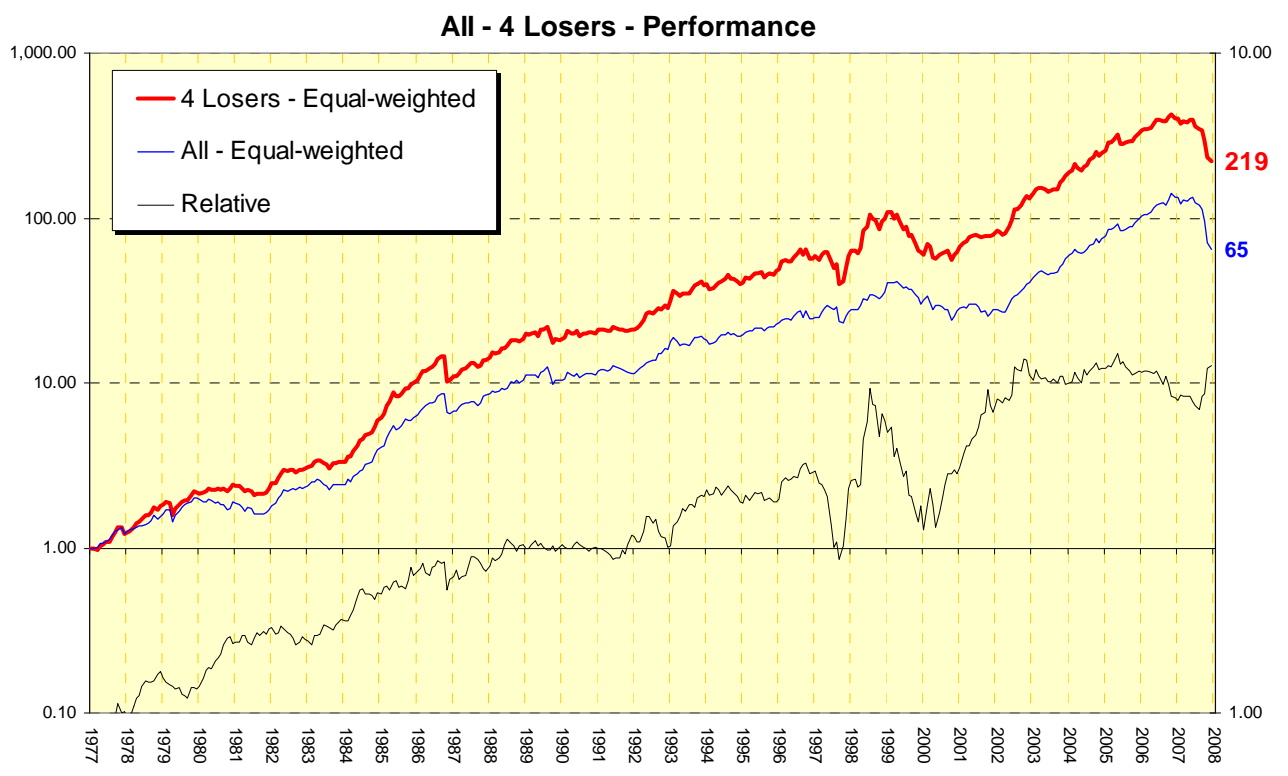

Figure 11: The performance of a portfolio of 4 countries following the 'loser' strategy, using the entire data-set from December 1969 and including countries in the analysis as their data became available. The strategy was best with a look-back period of 44 months and a holding period of 36 months.

From Figure 11 it can be seen that the 'loser' strategy using the entire data-set over the almost 40 years outperforms the equal weighted index. The trading strategy showed an annualised return of $19 \%$ over the period, significantly better than the benchmark's $14.5 \%$. As with the two previous analyses of the 'loser' strategy, the slope of the price-relative appears to flatten out in the more recent years. Furthermore, towards the end of 1997 the price relative shows a significant drop in performance, followed by strong out-performance for a year, which peaks in mid 1998, then falls for almost two years before steadily out-performing until 2003 when the graph flattens out. It is likely that this volatility around 1998 was a 
consequence of the East Asian financial crisis which severely affected emerging economies.

For the 'winner' strategy using the entire data-set, the best result was achieved for a portfolio of four equal weighted country indices using a formation period of 11 months and holding for the following one month. This portfolio achieved an annualised performance of 26\%; almost double that of the equal weighted benchmark at $13.9 \%$. Figure 12 shows the performance chart over the period.

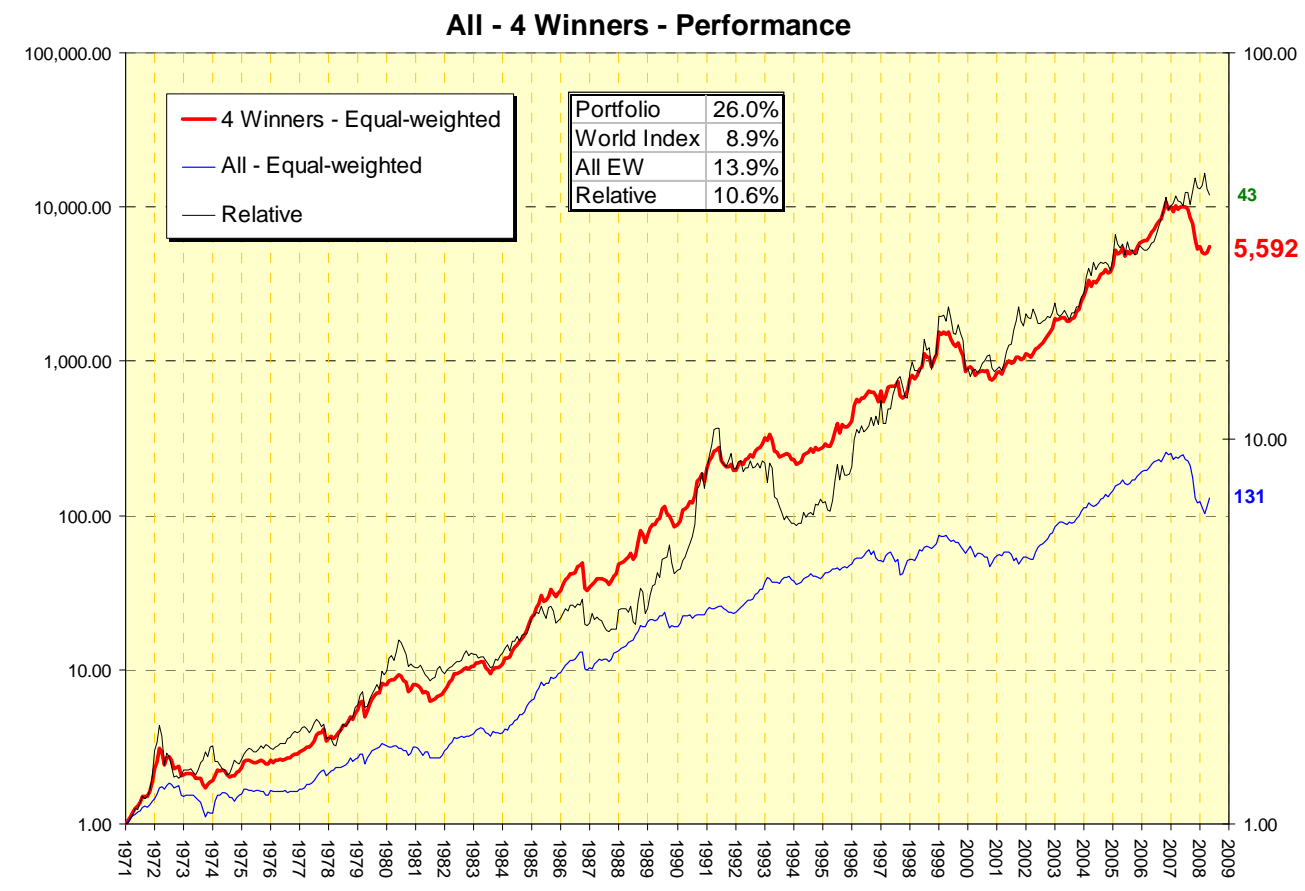

Figure 12: The performance of the portfolio of 4 'winners' using the entire data-set over the period December 1969 to May 2009.

From Figure 12 it can be seen that the 'winner' strategy using the entire data-set outperforms the equal weighted index and the price relative shows a steady upward trend throughout the 39 years, although some cycles are apparent in places. It is notable that the slope of the price relative over the first half of the time-series is lower than the latter half, indicating that the 'winner' strategy improved as additional country indices became available. On the whole, the strategy consistently and significantly outperforms the benchmark. 


\section{Conclusions}

Transaction costs were ignored in this analysis. Two types of costs need to be considered. Firstly, country indices can most easily be traded through $\mathrm{ETF}^{2} \mathrm{~s}$ which typically incur two types of cost; a management fee of between 10 and $75^{3}$ basis points (bp) per annum, and trading costs. Trading costs vary by trading platform and country index, but are typically around 25bp. An examination of the monthly churn in the portfolio revealed that individual country indices often remained in the portfolio for several review periods, requiring only an adjustment to their weights at the end of each holding period. Trading costs can also be significantly reduced by trading in futures contracts on ETFs, or trading through online platforms where lower rates apply. Even with trading costs, the results are likely to remain robust given the significant levels of out-performance identified.

The study examined almost 40 years of MSCI country index data for evidence of momentum and mean reversion. A momentum strategy identified 'winning' countries and held these in a portfolio over the succeeding months. A mean reversion strategy identified 'loser' countries and held these. All the combinations of formation period $(\mathrm{F})$, holding period $(\mathrm{H})$ and portfolio size $(\mathrm{N})$ were analysed and the resulting surface plot of portfolio out-performance against a benchmark was examined. To minimise the problem of data-mining the analysis was repeated using a second sample over a 21 year period, and repeated a third time by including new data into the sample as it became available. In all cases the analysis showed that a portfolio size of between 4 and 6 countries was optimal. Figure 13 summarises the results:

\begin{tabular}{|c|c|c|c|c|c|c|c|c|}
\hline $\begin{array}{l}\text { Sample } \\
\text { of MSCl } \\
\text { Country } \\
\text { Codes }\end{array}$ & $\begin{array}{l}\text { Period of } \\
\text { analysis }\end{array}$ & $\begin{array}{c}\text { Winner / } \\
\text { Loser }\end{array}$ & $\begin{array}{l}\text { Optimal } \\
\text { 'look-back' } \\
\text { period } \\
\text { (months) }\end{array}$ & $\begin{array}{l}\text { Optimal } \\
\text { holding } \\
\text { period } \\
\text { (months) }\end{array}$ & $\begin{array}{l}\text { Optimal } \\
\text { Portfolio } \\
\text { Size }\end{array}$ & $\begin{array}{c}\text { Equal } \\
\text { weighted } \\
\text { benchmark } \\
\text { annualised } \\
\text { return }\end{array}$ & $\begin{array}{l}\text { Optimal } \\
\text { portfolio } \\
\text { annualised } \\
\text { return }\end{array}$ & $\begin{array}{l}\text { Annualised } \\
\text { out - } \\
\text { performance }\end{array}$ \\
\hline Top 18 & $1968-2008$ & Loser & 54 & 36 & 5 & $12.4 \%$ & $15.4 \%$ & $2.5 \%$ \\
\hline Next 18 & $1986-2008$ & Loser & 56 & 22 & 4 & $10.3 \%$ & $20.7 \%$ & $9.4 \%$ \\
\hline All & $1968-2008$ & Loser & 44 & 36 & 4 & $14.5 \%$ & $19.0 \%$ & $4.0 \%$ \\
\hline Top 18 & $1968-2008$ & Winner & 10 & 2 & 5 & $12.4 \%$ & $17.7 \%$ & $4.7 \%$ \\
\hline Next 18 & $1986-2008$ & Winner & 10 & 1 & 6 & $9.4 \%$ & $16.4 \%$ & $6.4 \%$ \\
\hline All & $1968-2008$ & Winner & 11 & 1 & 4 & $13.9 \%$ & $26.0 \%$ & $10.6 \%$ \\
\hline
\end{tabular}

Figure 13: Summary of results

For the mean reversion (loser) strategy the optimal look-back period is between 44 and 56 months, and the holding period between 22 and 36 months. For the momentum (winner) strategy the optimal look back period is between 10 and 11 months and the holding period between 1 and 2 months. The consistency of these results, across different samples, is an indication of robustness of the findings.

\footnotetext{
${ }^{2}$ Although increasingly popular, ETFs are not yet available on all the country indices included in this study.

${ }^{3}$ The SATRIX40 for example, incurs a maximum management fee of 45bp per annum (Profile's Stock Exchange Handbook, October 2009 - January 2010, Profile Media, Johannesburg)
} 
In the case of the mean reversion strategy, an investor achieved an annualised outperformance of between $2.5 \%$ and $9.4 \%$ against the appropriate equal weighted benchmark. However, an examination of the effectiveness of the 'loser' strategy showed that most of the out-performance occurred in the early years, and that the benefits of the strategy diminished over time. There is therefore little indication that a mean reversion trading strategy will out-perform in the future.

The momentum strategy worked best at significantly shorter formation and holding periods and an investor following such a strategy would have shown annualised out-performance of between $4,7 \%$ and $10,6 \%$ against the equal weighted benchmarks. These results were found to be persistent over time, most likely on account of the significantly higher underlying value of country indices (compared to individual equities), making it difficult for market inefficiencies to be 'washedout'.

The significantly longer formation and holding period required for the mean reversion strategy are consistent with expectations. In contrast, momentum is shortlived; one to two months. The research also indicates that two or three years are needed for under-performing countries to achieve a re-rating by investors. The fact that these results are achieved using whole country indices suggests that global equity markets are relatively inefficient.

\section{References}

Bernard, V and Thomas J (1990): "Evidence that Stock Prices Do Not Fully Reflect the Implications of Current Earnings for Future Earnings”, Journal of Accounting and Economics, 3(4): 305-340.

Carhart, M (1997): “On Persistence in Mutual Fund Performance”, The Journal of Finance, 52(1): 5782.

Cochrane J (2001): Asset Pricing, Princeton: Princeton University Press.

Droms W. and Walker D (2001): “Performance Persistence of International Mutual Funds”, Global Finance Journal, 12(2): 237-248.

Fama E (1970): “Efficient Capital Markets: A Review of Theory and Empirical Work”, Journal of Finance, 25(2): 383-417.

Fraulo, P. and Nguyen J (2004): “Do industries explain momentum? - A replication of Moskowitz and Grinblatt (2004)” http://kanecap.com/doc/williams/econ18/2009/Fraulo_Nguyen_Econ18_2009.pdf accessed March 10, 2009.

De Bondt, W. and Thaler R (1985): “Does the Stock Market Over-react? ”, Journal of Finance, 40(3): 793-808.

Fama E (1998): "Market Efficiency, Long-term Returns and Behavioural Finance”, Journal of Financial Economics, 43(9): 283-306.

Fama, E. and French K (1992): “The Cross-section of Expected Stock Returns”, Journal of Finance, 47(2): 427-465. 
Fama, E. and French K (1996): "Multifactor Explanation of Asset Pricing Anomalies", Journal of Finance, 55(1): 55-84.

George, T J and Hwang C (2004): “The 52-week High and Momentum Investing”, Journal of Finance, 59(5): 2145-2176.

Grinblatt, M. and Moskowitz T (2004): "Predicting Stock Price Movements from Past Returns: The Role of Consistency and Tax-loss Selling”, Journal of Financial Economics, 71(3): 541-579.

Jegadeesh N and Titman S (1993): "Returns to Buying Winners and Selling Losers: Implications to Stock Market Efficiency”, Journal of Finance, 48(1): 65-92.

Jegadeesh N and Titman S (2001): "Profitability of Momentum Strategies: An Evaluation of Alternative Explanations, Journal of Finance, 56(2): 699-720.

Lakonishok J and Vermaelen T (1990): “Anomalous Price Behaviour Around Repurchase Tender Offers”, Journal of Finance, 45(2): 455-478.

Moskowitz, T and Grinblatt M (1999): “Do Industries Explain Momentum?”, Journal of Finance, 54(4): 1249-1290.

Ross S (1976): “The Arbitrage Theory of Capital Asset Pricing”, Journal of Economic Theory, 13(3): 342-360. 